\title{
Heat Transfer and Granule Growth Rate in Fluidized Bed Granulation
}

\author{
Satoru Watano, ${ }^{*}$ Toru Fukushima, and Kei Miyanami \\ Department of Chemical Engineering, University of Osaka Prefecture, 1-1 Gakuen-cho, Sakai, Osaka 593, Japan. \\ Received September 14, 1995; accepted December 1, 1995
}

In this study, the mechanism of heat transfer between gas and granule in fluidized bed granulation was investigated, and the granule growth rate was predicted using heat transfer and moisture balance measurements. First of all, the heat transfer coefficient between gas and granules in a fluidized bed was measured using granules of four different sizes, and the experimental data obtained over a wide range of granule Reynolds number were found to be expressed as $N u_{\mathrm{p}}=2+0.6 R e_{\mathrm{p}}^{1 / 2} \operatorname{Pr}^{1 / 3}$, where $N u_{\mathrm{p}}, R e_{\mathrm{p}}$ and $P r$ indicate granule Nusselt number, Reynolds number and Prandtl number, respectively. Secondly, a model in which the heat transfer and the moisture balance were taken into consideration was proposed to predict the moisture content and granule growth rate during granulation. It was also confirmed that the experimental results at various binder (water) flow rates and inlet air temperatures were in good agreement with those predicted from the theory. As a result, the mechanism of the heat transfer was elucidated and the granule growth rate during granulation could be predicted with high accuracy.

Key words granule growth rate; heat transfer; moisture balance; moisture content; granulation; fluidized bed

Fluidized bed has been widely utilized in chemical and other industries, making use of its good characteristics of heat and mass transfer, high contact efficiency and good mixing of solid particles. In powder handling processes, these important features of the fluidized bed are used effectively for powder granulation, as the name implies, a particle size enlargement process.

Fluidized bed granulation is carried out by spraying a binder solution on the fluidizing powdered materials. The role of various operating variables and the mechanism of agglomeration in the fluidized bed have been the subject of extensive investigations. Davis and Gloor, ${ }^{1,2)}$ Rankel et al., ${ }^{3)}$ and Ormos et al. ${ }^{4,5)}$ have studied the effects of the operating variables such as binder concentration, binder feed rate, spray mist size, inlet air temperature and moisture content on granule growth experimentally, while Shæfer and Wørts ${ }^{6-8)}$ have systematically and quantitatively investigated these operating variables. Although most of the studies have the same conclusion that the moisture content is the most important factor in determining granule growth in fluidized bed granulation, there have been no studies which addressed the analysis of the granule damping process and its mechanism. Also, the heat transfer mechanism is of great importance in analyzing the granule damping process or determining the optimum operational conditions in fluidized bed granulation: however, there also have been no studies related to heat transfer during fluidized bed granulation.

The purpose of this contribution is to analyze the mechanism of heat transfer between gas and granules, and to theoretically predict the moisture content and the granule growth rate in fluidized bed granulation. The heat transfer coefficient between gas and granules was measured and the relation between granule Nusselt number and granule Reynolds number was investigated. A model in which the heat transfer and the moisture balance were taken into consideration was proposed to predict the moisture content and granule growth rate during granulation. To confirm the validity of the model, experimental data at various feed rates of spray liquid and inlet air temperatures were compared with those predicted

* To whom correspondence should be addressed. from our theory.

\section{Experimental}

Equipment An outline of an experimental apparatus is shown in Fig. 1. The main body of the fluidized bed was a transparent column made of polymethylmethacrylic resin with an inner diameter of $0.125 \mathrm{~m}$ and a height of $1.00 \mathrm{~m}$. To avoid heat loss, the column was covered with a polyurethane heat insulator. An air distributor consisted of a perforated stainless steel plate with 1200 holes of $0.001 \mathrm{~m}$ in diameter in a triangular arrangement, surmounted by a 200 mesh stainless steel screen. Heated air was used as the fluidizing air, and water as a binder liquid was sprayed by a binary nozzle located $0.60 \mathrm{~m}$ above the distributor. Entrained granules were collected by a cyclone, in which a small amount of fine ungranulated granules less than $1 \%$ were actually collected.

The temperature of the fluidizing air was measured by a hot wire thermometer, which was covered by a 200 mesh stainless screen to avoid the sensor from contacting the granule particles. The granule surface temperature was measured by a thermocouple, of which the pointed end was directed at the central axis of the column and was in contact with the powder bed. Both sensors were located $0.10,0.20$ and $0.40 \mathrm{~m}$ above the bottom air distributor.

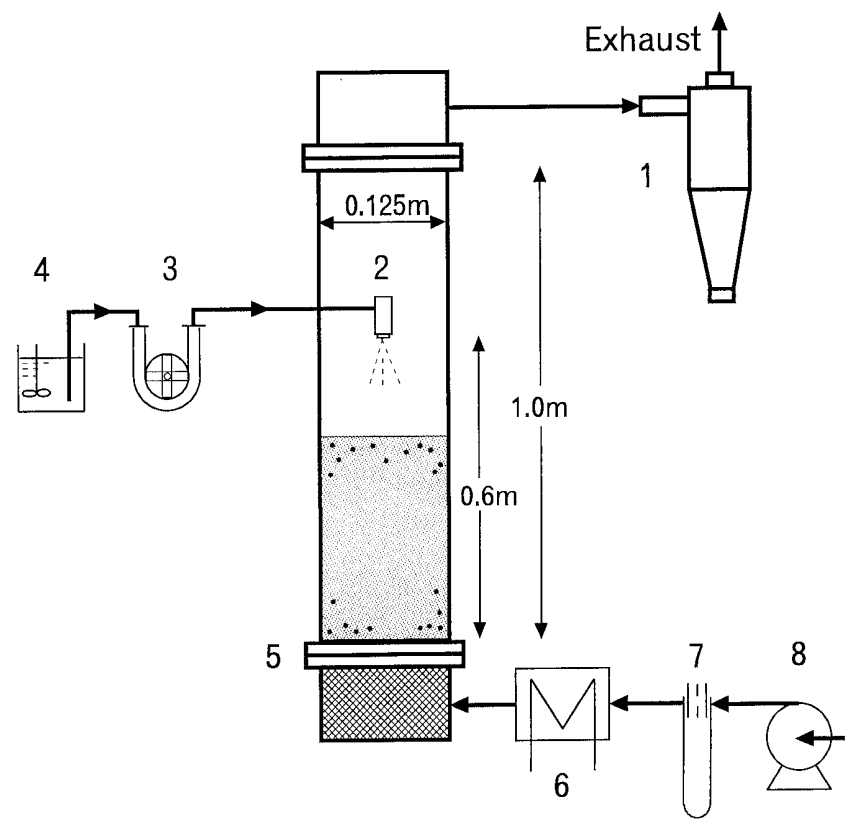

Fig. 1. Schematic Diagram of Experimental Set Up Employed

1 , cyclone collector; 2 , spray nozzle; 3 , roller pump; 4 , binder liquid; 5 , distributor; 6 , heater; 7 , orifice flow meter; 8 , blower.

(C) 1996 Pharmaceutical Society of Japan 
Table 1. Powder Samples Used

\begin{tabular}{lcc}
\hline \hline \multicolumn{1}{c}{ Sample } & $\begin{array}{c}\text { Number median } \\
\text { diameter } \\
(\mu \mathrm{m})\end{array}$ & $\begin{array}{c}\text { Mixing weight } \\
\text { ratio } \\
(-)\end{array}$ \\
\hline Lactose $^{a)}$ & 60 & 0.7 \\
Cornstarch $^{b)}$ & 15 & 0.3 \\
Hydroxypropylcellulose $^{c)}$ & 21 & 0.05 \\
$\quad$ Total & & 1.05 \\
\hline
\end{tabular}

a) Pharmatose $200 \mathrm{M}$, DMV. b) Cornstarch W, Nippon Shokuhin Kakou Co., Ltd. c) HPC-EFP, Shin-Etsu Chemical Co., Ltd.

Table 2. Operating Conditions

$\begin{array}{ll}\text { Fluidizing air velocity } & 0.8 \mathrm{~m} / \mathrm{s} \\ \text { Minimum fluidizing air velocity } & 0.071 \mathrm{~m} / \mathrm{s} \\ \text { Air temperature } & 313-353 \mathrm{~K} \\ \text { Binder (water) feed rate } & 1.18 \times 10^{-4}-2.29 \times 10^{-4} \mathrm{~kg} / \mathrm{s} \\ \text { Spray air pressure } & 1.5 \times 10^{5}-2.3 \times 10^{5} \mathrm{~Pa} \\ \text { Spray mist size } & 35 \mu \mathrm{m}\end{array}$

The inlet and outlet air temperatures and humidities were measured by ceramic sensors. The inlet air flow rate was measured by an orifice flow meter. The inlet air temperature and the inlet air flow rate were feedback controlled to maintain a stable operation. The sensor output signals, simultaneously digitized in a 12 bit $\mathrm{A} / \mathrm{D}$ converter, were monitored by a personal computer.

Powder Samples Table 1 lists the properties of the power samples used. The starting materials for granulation were $0.300 \mathrm{~kg}$ in weight, consisting of lactose and cornstarch (charge ratio is $7: 3$ by weight) $0.015 \mathrm{~kg}$ of hydroxypropylcellulose (HPC EF-P) was used as a binder, which was mixed as a dry powder into the starting materials before granulation. This formulation is referred to as "Pharmaceutical standard formulation" by the working group of the Society of Powder Technology Japan for the preparation of standard formulations. ${ }^{9)}$

Evaluation of Granules The droplet size distribution of binder liquid (water) in spraying was measured by a light scattering method using a He-Ne laser beam (LDSA-1300A, Meiwashoji Co., Ltd.) at room temperature and humidity.

The mass based particle size distribution of granules was measured by sieve analysis with a rowtap shaker (ES-65, lida Manufacturing Co., Ltd.). About $2 \times 10^{-3} \mathrm{~kg}$ of granules were shaken for $180 \mathrm{~s}$. After measuring the weight of granules on each sieve, the mass-based particle size distribution was calculated based on a log-normal distribution using a personal computer.

The number median diameter of the powder samples (Table 1) was measured using an image processing system (Image Eye, Fuji Paudal Co., Ltd.). ${ }^{10)}$

The apparent density of the granules was measured using a powder tester (Hosokawa Micron Co., Ltd.).

Operating Conditions The operating conditions used are listed in Table 2 . In this study, the fluidizing air velocity was selected to be $0.8 \mathrm{~m} / \mathrm{s}$ for the following reasons: in the case of a low fluidizing air velocity coarse granules were produced due to unfavorable granular flow or circulation. This caused a relatively wide particle size distribution. By contrast, when the fluidizing air velocity was considerably high, granules with a narrow particle size distribution could be produced due to the good mixing or dispersion of spray mist and granules. However, when the air velocity was too high, granules were difficult to grow because of a large separation force caused by the fluidizing air. In this case, a fraction of fine granules under $75 \mu \mathrm{m}$ also increased markedly because of granule attrition. As a result, the optimum fluidizing air velocity was determined to be $0.8 \mathrm{~m} / \mathrm{s}$, because the narrowest particle size distribution with a high yield of $75-500 \mu \mathrm{m}$ granule was obtained constantly at $W=18 \%$. Here, the yield of 75-500 $\mu \mathrm{m}$ was defined by "The Pharmacopoeia of Japan"11 as the subtilized granule for oral dosage form, and the $W=18 \%$ was the optimum operating moisture content, which has frequently been used in the pharmaceutical industry to produce subtilized granules by fluidized bed granulation. In addition, the segregation of granules was seldom observed under these operating conditions, and granules of almost uniform density and size ( $=$ geometric standard deviation was 1.3 ) were produced.

To vary the damping speed during granulation, three levels of liquid flow rate were used. The mass median diameter of the measured spray mist increased almost linearly from 35 to $45 \mu \mathrm{m}$ with an increase in the liquid flow rate. To keep a constant mass median diameter of the spray mist $(35 \mu \mathrm{m})$ during every run, regardless of the liquid flow rate variation, the spray air pressure was varied from $1.5 \times 10^{5}$ to $2.3 \times 10^{5} \mathrm{~Pa}$.

Heat Transfer between Gas and Granules During the fluidized bed granulation, granules were dampened, and simultaneously, dried by the fluidizing heated air. The granule moisture content was thus determined by the dampening and the drying speed; the dampening speed is rather easily calculated by the binder liquid flow rate and the rate of water carried by the humid fluidizing air and spraying air, while computation of the drying speed requires an accurate heat transfer coefficient between gas and granule. Therefore, we here tried to calculate the heat transfer coefficient between gas and granule first.

For the measurement of the heat transfer coefficient, the following assumptions were used:

(1) an adiabatic condition

(2) radial air temperature distribution could be neglected

(3) the gas and the spray mist were perfectly mixed

(4) all the spray mist was adhered onto the granule particle, and the thermal energy supplied from the heated air to the granules was totally consumed to dry the granule surface water given by the spray mist.

Among the above four assumptions, the second assumption, that the radial air temperature distribution could be neglected, was confirmed practically, because the air temperature difference between the center and the wall was within $1 \mathrm{~K}$. The third assumption, that the binder mist was perfectly mixed with the gas, was also confirmed by using a tracing binder liquid; the time constant, in which the binder mist was perfectly mixed, was within $10 \mathrm{~s}$. The fourth assumption was also confirmed by the results of coating experiments; in an aqueous coating ${ }^{12)}$ in which a suspension of aqueous methacrylate co-polymer was sprayed onto core spherical particles, the coating efficiency exceeded $90 \%$, and the water was evaporated from the granule surface after the spray mist was definitely stuck onto the granule surface. Therefore, the heat of spray drying, in which the spray mist was dried before sticking onto the granule surface, seemed to be neglected.

We allowed the inlet humid air, having a temperature of $T_{\text {in }}$ and a humidity of $H_{\mathrm{in}}$, to be exhausted at a temperature of $T_{\mathrm{out}}$. The decrease in the air sensible heat, $q_{1}$, can be estimated as

$$
q_{1}=G_{\mathrm{g}} \cdot C_{\mathrm{H}}\left(T_{\text {out }}-T_{\mathrm{in}}\right)
$$

where $G_{\mathrm{g}}$ is the mass flow rate of dry air and $C_{\mathrm{H}}$ is the humid air heat capacity defined as

$$
C_{\mathrm{H}}=1005+1884 H_{\mathrm{in}}
$$

The rate of heat transfer from air to granules $\left(q_{2}\right)$ is expressed as

$$
q_{2}=h_{\mathrm{p}} \cdot A \cdot\left(T_{\text {out }}-T_{\mathrm{p}}\right)
$$

where $h_{\mathrm{p}}$ is the heat transfer coefficient between gas and granules, $T_{\mathrm{p}}$ is the granule surface temperature, and $A$ is the gas-granule interfacial area, respectively.

In the preliminary study, it was confirmed that the air temperature decreased rapidly and reached a thermal equilibrium soon after the air passed through the distributor. Thus, the temperature difference between $T_{\mathrm{p}}$ and $T_{\text {out }}$ was measured when the air reached a thermal equilibrium with the granules.

In Eq. 3, the gas-granule interfacial area is calculated by the following equation on the basis of an assumption that the granule surface area contributes effectively to the heat transfer:

$$
A=\frac{6(1-\varepsilon) V}{d_{\mathrm{p}} \phi_{\mathrm{c}}}
$$

where $V$ and $d_{\mathrm{p}}$ show the mean volume of fluidized bed and the granule diameter, respectively. Also, $\phi_{\mathrm{c}}$ indicates a specific surface shape factor of granule ${ }^{13)}$ which is defined by

$$
\phi_{\mathrm{c}}=\frac{\phi_{\mathrm{v}}}{\phi_{\mathrm{s}}}=\frac{v / \frac{\pi}{6} d_{\mathrm{p}}^{3}}{s / \pi d_{\mathrm{p}}^{2}}
$$

where, $\phi_{\mathrm{v}}, \phi_{\mathrm{s}}, v$ and $\mathrm{s}$ show the volume shape factor, surface shape factor, granule volume and granule surface area, respectively. In addition, $\varepsilon$ expresses a void fraction calculated by 


$$
\varepsilon=1-\frac{M}{\rho_{\mathrm{w}} A_{\mathrm{f}} L_{\mathrm{f}}}
$$

where, $M, A_{\mathrm{f}}$ and $L_{\mathrm{f}}$ indicate granule wet mass, the cross sectional area of the column and the fluidized bed height, and $\rho_{\mathrm{w}}$ denotes the granule wet density, which has been measured using the powder tester.

Assuming that all the decrease in the air sensible heat is used up by the heat transfer from gas to granules $\left(q_{1}=q_{2}\right)$, the following expression is derived

$$
h_{\mathrm{p}} \cdot A \cdot\left(T_{\text {out }}-T_{\mathrm{p}}\right)=G_{\mathrm{g}} \cdot C_{\mathrm{H}} \cdot\left(T_{\text {in }}-T_{\text {out }}\right)
$$

By using Eq. 7, the heat transfer coefficient $h_{\mathrm{p}}$ can be estimated.

\section{Results and Discussion}

Measurement of Heat Transfer Coefficient Figure 2 presents the granule Nusselt number $N u_{\mathrm{p}}\left(=h_{\mathrm{p}} \cdot d_{\mathrm{p}} / \lambda_{\mathrm{g}}\right)$ as a function of the granule Reynolds number $R e_{\mathrm{p}}$ $\left(=d_{\mathrm{p}} \cdot v \cdot \rho_{\mathrm{g}} / \mu_{\mathrm{g}}\right)$ at various granule sizes. Here, $\lambda_{\mathrm{g}}, \rho_{\mathrm{g}}$ and $\mu_{\mathrm{g}}$ show the thermal conductivity, density and viscosity of the air, respectively. The velocity $v$ in $R e_{\mathrm{p}}$ is defined by $u / \varepsilon$, where $u$ shows the fluidizing air velocity. In this experiment, granules which had been previously agglomerated and sieved into four levels of granule size, were used.

From Fig. 2, it can be seen that the granule Nusselt number was almost linearly correlated with the granule Reynolds number, and the effects of granule size on the granule Nusselt number could be neglected.

To compare the present data with literature, the data of Ranz and Marshall ${ }^{14)}$ is described in Fig. 2. Here, $\mathrm{Pr}$ $\left(=C_{\mathrm{p}} \mu_{\mathrm{g}} / \lambda_{\mathrm{g}}\right)$ is the Prandtl number, which expresses the thermal characteristics of a fluid. It was found that the agreement between the obtained results and the published ones was satisfactory; as Watanabe et al. ${ }^{15}$ ) have already reported, each granule in the fluidized bed moves almost independently within the region of $10 \leqq R e_{\mathrm{p}} \leqq 100$, and interaction between the granules is thought to be very small in this region. Therefore, it could be concluded that the Ranz-Marshall equation (Eq. 8) could be used for calculating the heat transfer coefficient.

$$
N u_{\mathrm{p}}=2+0.6 \operatorname{Re}_{\mathrm{p}}^{1 / 2} \operatorname{Pr}^{1 / 3}
$$

Granule Growth in Fluidized Bed Granulation Figure 3 shows experimental results of the relation between granule mass median diameter and operational moisture content during granulation. As previously reported, ${ }^{16-18)}$ the

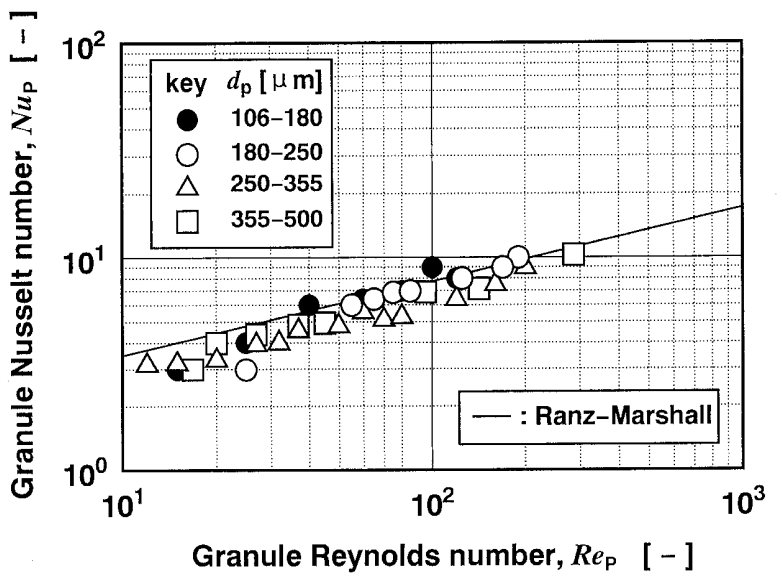

Fig. 2. Heat Transfer between Gas and Granules in Fluidized Bed Granulation granule mass median diameter increased linearly with an increase in moisture content; slow granule growth in the region of $0 \leqq W \leqq 7 \%$ was followed by rapid granule growth above the moisture content of $W=7 \%$. In the low moisture content range, liquid bridges could not be formed as well on the granule surface because the granules were porous enough to absorb the water on the granule surface. By contrast, since the granule interior was filled with water to some extent above the moisture content of $W=7 \%$, liquid bridges were formed rapidly and rapid granule growth took place. In both cases, it was found that the granule diameter could be estimated from the moisture content, since a linear correlation between the granule diameter and the moisture content was obtained.

Here, it has already been confirmed that almost the same relationship between the mass median diameter and the moisture content was obtained if the fluidization air velocity varied from $u=0.6$ to $1.2 \mathrm{~m} / \mathrm{s}$, although slight differences were found in the particle size distribution and yield of granules. These results implied that the separation force under these experimental conditions was small enough compared to the adhesion force by the liquid bridge between the particles. In these cases, it has been reported that the granule median diameter is well expressed by the moisture content; during granulation, the force which makes particles coalesce (adhesion force by liquid bridge) is closely related to the amount of binding liquid (i.e. moisture content of granules) ${ }^{19,20)}$ and the force which pulls apart the adhered particles is caused by separation force ${ }^{21-23)}$ due to gravity, mechanical agitation, vibration, and so on, which depends on the type of granulation equipment used. If the separation force is relatively small compared to the adhesion force, the granule diameter is dependent on the adhesion force. It has been reported that the adhesion force by the liquid bridge is determined by the liquid bridge shape, ${ }^{24,25)}$ and the shape is expressed by atmospheric humidity, liquid volume and liquid properties. Since the liquid properties are constant during the granulation experiment, the granule diameter is considered to be determined by the liquid volume, i.e., the granule moisture content. It has already been described that the mass median diameter of granules during fluidized bed granulation is a function of the moisture content ${ }^{16-18)}$ and granule growth can be controlled by

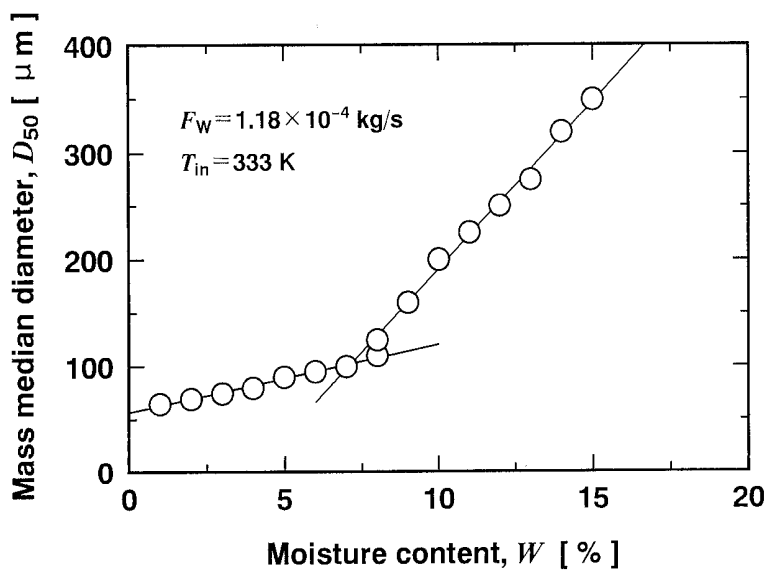

Fig. 3. Relation between Granule Mass Median Diameter and Moisture Content 
monitoring the moisture content. ${ }^{17,18,26)}$ It has also been shown that the binder spraying conditions, such as water damping speed ${ }^{17)}$ and spray mist diameter, ${ }^{19,20)}$ also affect granule diameter, but the effects are much smaller than the moisture content. In this study, we have tried to predict the moisture content by heat transfer and moisture balance, hence the granule growth rate during fluidized bed granulation was predicted using the relationship between the moisture content and the granule mass median diameter obtained in Fig. 3.

Prediction of the Moisture Content The moisture content was attempted to be calculated by using heat transfer and moisture balance measurements.

Moisture balance during granulation is written as

$$
\left(\begin{array}{c}
\text { rate of water } \\
\text { accumulation }
\end{array}\right)=\left(\begin{array}{c}
\text { rate of water } \\
\text { transported in }
\end{array}\right)-\left(\begin{array}{c}
\text { rate of water } \\
\text { exhausted }
\end{array}\right)
$$

The rate of water transported into the fluidized bed is calculated by the binder liquid (water) flow rate and the rate of water carried by the humid inlet air and sprayed air. The rate of water exhausted from the bed, $F_{\mathrm{w}, \text { out }}$, is calculated by the evaporation speed of water by the heat transfer:

$$
F_{\mathrm{w}, \text { out }}=h_{\mathrm{p}} \cdot A \cdot\left(T_{\text {out }}-T_{\mathrm{p}}\right) / r_{\mathrm{w}}
$$

where $r_{\mathrm{w}}$ denotes the latent heat of water evaporation. In this equation, it is assumed that the drying takes place a constant-rate period, because the granule surface temperature measured was almost the same as the wet bulb temperature.

The amount of water accumulated in the granules $\left(M_{\mathrm{w}}\right)$ is obtained by integrating the water accumulation speed. The granule moisture content is thus calculated by the following equation,

$$
W=\frac{M_{\mathrm{w}}}{M_{\mathrm{w}}+M_{\mathrm{p}}} \times 100
$$

where $M_{\mathrm{p}}$ is the mass of dry granule.

Figure 4 illustrates the effect of moisture content $W$ on the hold up $(=1-\varepsilon)$ and gas-granule interfacial area $A$. As seen from Fig. 4, the value of hold up was within the range of 0.09 to 0.10 , showing the fluidized bed was considerably free of granules. Although the bed height

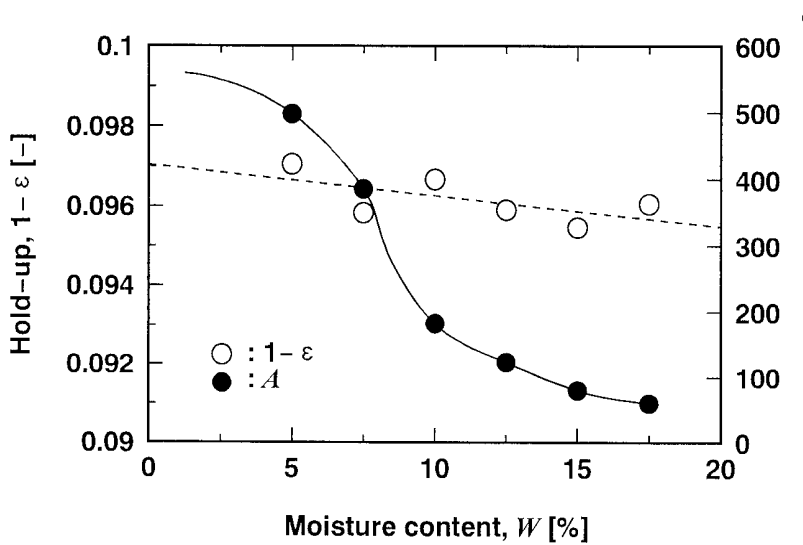

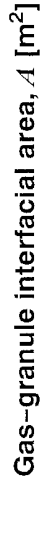

Fig. 4. Relation between Granule Hold-Up, Gas-Granule Interfacial Area and Moisture Content during granulation decreased with an increase in the moisture content, the effect of the bed height decrease on the void fraction was regarded to be small. It was therefore concluded that once the moisture content was determined, the voidage $\varepsilon$ and the gas-granule interfacial area $A$ could be estimated.

In calculating the rate of water accumulation (Eq. 10), an adequate value of $A$ must be substituted into Eq. 10 . By using the calculated water accumulation rate, moisture content is determined by Eq. 11. Then, $A$ is computed again using the results obtained in Fig. 4, and compared with the initial value of $A$. By repeating this trial and error, the gas-granule interfacial area and moisture content can be calculated.

Figure 5 illustrates the moisture content at various liquid flow rates. In this figure, the solid line indicates the predicted moisture content and the plots present the measured moisture content. It was found that the theoretical results were in good agreement with the results of the experiments, and that moisture content at various liquid flow rates could be predicted with high accuracy.

Figure 6 also illustrates moisture content at various inlet air temperatures. In this case, the theoretical results were also in good agreement with the results of the experiments.

As a result, the moisture content during granulation could be predicted numerically using the heat and moisture balances. The obtained results also imply that the heat transfer coefficient calculated by using pre-granulated particles could be applied to the actual granulation system.

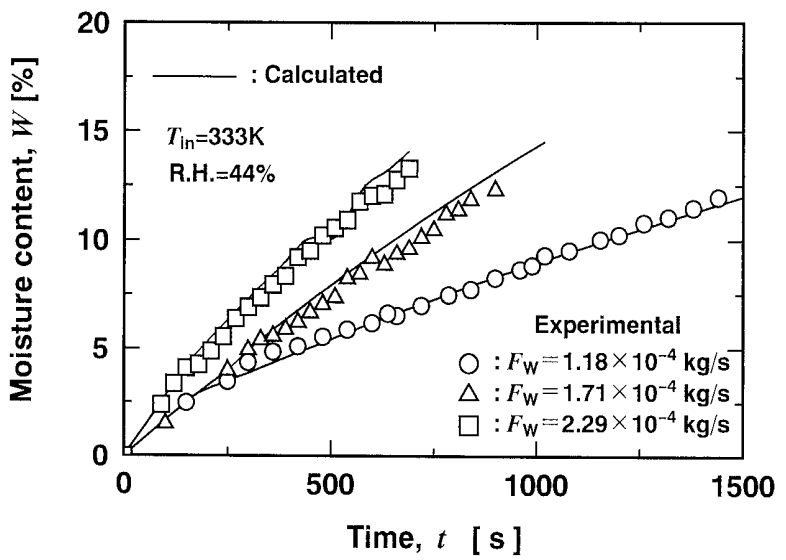

Fig. 5. Effects of Liquid Flow Rate on Granule Moisture Content

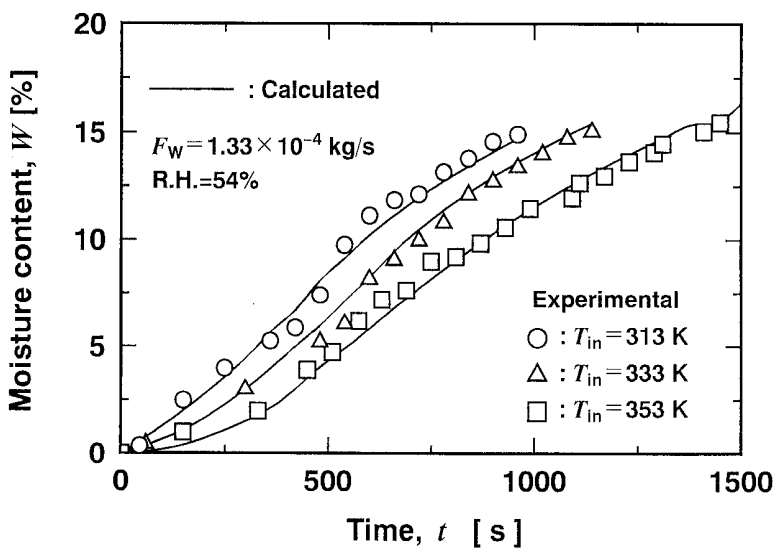

Fig. 6. Effects of Inlet Air Temperature on Granule Moisture Content 


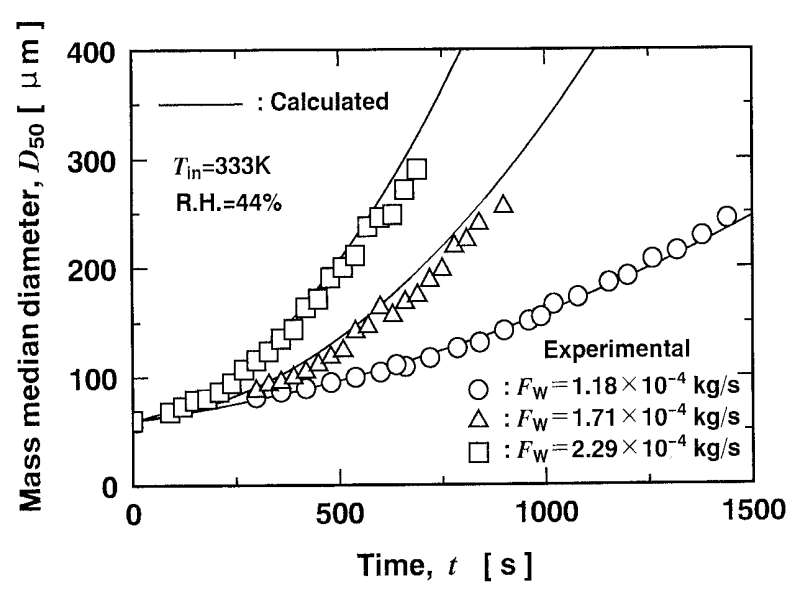

Fig. 7. Effects of Liquid Flow Rate on the Granule Growth Rate

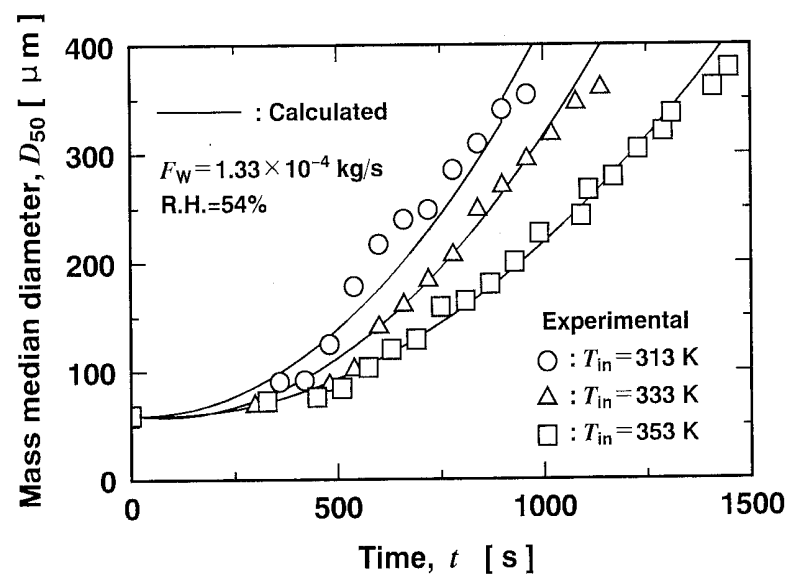

Fig. 8. Effects of Inlet Air Temperature on the Granule Growth Rate

It was suggested that the dispersion of the spray mist was considerably good, and that water sprayed onto the granule surface was absorbed quickly and simultaneously evaporated from the surface.

Granule Growth Rate in Fluidized Bed Granulation As previously described, granule mass median diameter is well expressed by moisture content under fixed operational conditions. If the moisture content during granulation is calculated numerically, granule diameter change can be predicted using the relationship between moisture content and granule diameter. In this study, we have tried to predict granule growth rate using the calculated moisture content.

Figure 7 illustrates the effects of liquid flow rate on the granule growth rate. In this figure, the solid line indicates the calculated mass median diameter of granules, and the plots present the experimental results. It was found that the theoretical results were in good agreement with the results of the experiments, and that the granule growth rate at various liquid flow rates could be predicted with high accuracy. It could also be said that the measurement of the heat transfer coefficient was proven to be conducted correctly.

Figure 8 shows the effects of inlet air temperature on the granule growth rate. Without the scattering of data, the agreement between the results of calculation and experiment was considered to be very good. It could also be said that the granule growth rate at various inlet air temperatures could be predicted with high accuracy.
As a result, the heat transfer mechanism was elucidated and the water dampening process was analyzed numerically. The obtained information will be of great use in calculating the liquid spray rate or feed condition of fluidizing air in optimizing operating conditions in laboratory scale experiments, or in estimating the optimum operating conditions in the granulation scale-up.

\section{Conclusions}

On the analysis of the heat transfer mechanism in fluidized bed granulation, the heat transfer coefficient between gas and granules was measured and an empirical equation for the heat transfer has been derived. A model in which heat transfer and moisture balance were taken into consideration has been proposed to predict the moisture content and the growth rate of granule size during granulation. It was found that the experimental results for various liquid flow rates and inlet air temperatures have shown to be in extremely good agreement with the predicted data. As a result, the heat transfer mechanism could be elucidated, and the granule growth rate in fluidized bed granulation could be simulated with high accuracy.

\section{References}

1) Davis W. L., Gloor W. T., J. Pharm. Sci., 60, 869-1874 (1971).

2) Davis W. L., Gloor W. T., J. Pharm. Sci., 61, 618-622 (1971).

3) Rankell A. S., Scott M. W., Lieberman H. A., Chow F. S., Battista J. V., Hung. J. Ind. Chem., 53, 320-324 (1964).

4) Ormos Z., Pataki K., Csukas B., Hung. J. Ind. Chem., 1, 307-328 (1973).

5) Ormos Z., Pataki K., Csukas B., Hung. J. Ind. Chem., 1, 463-474 (1973).

6) Schæfer T., Wørts O., Arch. Pharm. Chem. Sci., 5, 178-193 (1977).

7) Schæfer T., Wørts O., Arch. Pharm. Chem. Sci., 6, 1-13 (1978).

8) Schæfer T., Wørts O., Arch. Pharm. Chem. Sci., 6, 14-25 (1978).

9) Sunada H., Kokubo H., Proceeding of Agglos 93', Nagoya, November 1993, pp. 873-878.

10) Watano S., Miyanami K., Powder Technol., 83, 55-60 (1995).

11) "The Pharmacopoeia of Japan," Vol. 12, ed. by The Society of Japanese Pharmacopoeia, Yakuji-Nippo, Tokyo, 1991.

12) Watano S., Takaya H., Wada I., Miyanami K., Chem. Pharm. Bull., 42, 2338-2341 (1994).

13) Masuda H., "Huntaikougaku No Kiso," Nikkan Kougyou Shinbun. 1st ed., Tokyo, 1992, p. 46.

14) Ranz W. E, Marshall M. R., Chem. Eng. Prog., 48, 141-146 (1952).

15) Watanabe T., Chen Y., Naruse I., Hasatani M., Kagaku Kogaku Ronbunshu, 18, 601-606 (1992).

16) Shinoda A., Nasu T., Furukawa M., Sakashita S., Uesugi K., Miyake Y., Toyoshima S., Yakuzaigaku, 36, 83-88 (1972).

17) Watano S., Terashita K., Miyanami K., Advanced Powder Technol., 3, 255-265 (1992).

18) Watano S., Terashita K., Miyanami K., Chem. Pharm. Bull., 39, 1013-1017 (1991).

19) Watano S., Fukushima T., Miyanami K., J. Chem. Eng. Jpn., 28, 8-13 (1995).

20) Watano S., Yamamoto A., Miyanami K., Chem. Pharm. Bull., 42, 133-137 (1994).

21) Watano S., Morikawa T., Miyanami K., J. Chem. Eng. Jpn., 28, 171-178 (1995).

22) Huang C. C., Kono H. O., Powder Technol., 55, 19-34 (1988).

23) Huang C. C., Kono H. O., Powder Technol., 55, 35-49 (1988).

24) Endo T., Kousaka Y., Nishie Y., Kagaku Kogaku Ronbunshu, 18, 942-949 (1992).

25) Endo T., Kousaka Y., Nishie Y., Kagaku Kogaku Ronbunshu, 18, $950-955$ (1992).

26) Watano S., Sato Y., Miyanami K., J. Chem. Eng. Jpn., 28, 282-287 (1995). 